\title{
Adjuvant chemotherapy for stage II colon cancer: who really needs it
}

\author{
Yan Yangl,* \\ Yang Yang ${ }^{2, *}$ \\ Hui Yang' \\ Fen Wang' \\ Huihui Wang' \\ Qi Chen' \\ Ying Liu' \\ Aiying $\mathrm{Li}^{\prime}$ \\ Quanan Zhang'
}

'Department of Oncology, the Affiliated Jiangning Hospital with Nanjing Medical University, Nanjing, People's Republic of China; ${ }^{2}$ Department of Medicine, Medical University of South Carolina (MUSC),

Charleston, SC, USA

*These authors contributed equally to this work
Correspondence: Quanan Zhang

Department of Oncology, the Affiliated Jiangning Hospital with Nanjing Medical University, I 68 Gushan Road, Nanjing

21 I 100, People's Republic of China

Tel +86 25 5II 9 II 00

Fax +86 $255228 \quad 1256$

Email 13905152166@139.com
This article was published in the following Dove Press journal:

Cancer Management and Research

Background: Although there is evidence that failure to reach the baseline of 12-13 lymph nodes in resected specimens is related to poor prognosis of patients with stage II colon cancer, and may be a marker of adjuvant therapy, the use of these markers remains controversial. The objective of this study was to determine the advantage of chemotherapy treatment in patients with stage II colon cancer on the basis of the number of lymph nodes examined in radical surgery. Patients and methods: Using monitoring, epidemiology, and final outcome Medicare database, we authenticated 9,651 patients aged $\geq 66$ years diagnosed with resected stage II colon cancer from 1999 to 2004 . Medical insurance claims determined the adoption of chemotherapy within 3 months after radical operation. The relation between patient/tumor characteristics (including the number of lymph nodes examined) and the use of adjuvant chemotherapy was tested using chi-squared test and multiple logistic regression. Multivariate Cox model was used to compare survival rates between the treatment and untreated groups.

Results: Most patients (54.8\%) had only 1-12 lymph nodes examined, while only $41.6 \%$ of the patients had $>12$ lymph nodes examined. Overall, $20.9 \%$ of patients received adjuvant chemotherapy; there was no relationship between chemotherapy and the number of lymph nodes examined $(P=0.984)$. The presence of 12 or fewer lymph nodes in surgical specimens was related to poor overall survival (OS; adjusted hazard ratio [HR] 1.31, 95\% CI 1.21-1.41). Although adjuvant chemotherapy was related to our cohort improvement, its beneficial effects on OS (HR: 0.73 ; 95\% CI: 0.64-0.83) and disease-free survival (HR: 0.71; 95\% CI: 0.60-0.85) only existed in patients with 0-12 lymph nodes examined.

Conclusion: The presence of 12 or fewer lymph nodes in surgical specimens is related to poor prognosis and survival benefit in adjuvant chemotherapy for stage II colon cancer patients. More attention should be paid to the implementation of recommendations for lymph node dissection to help identify patients who really benefit from adjuvant chemotherapy after colectomy.

Keywords: colon cancer, chemotherapy, prognosis

\section{Introduction}

Currently colorectal cancer (CRC) accounts for the third highest cancer mortality rate in the USA. ${ }^{1,2}$ It was estimated that there would be 135,430 new colorectal cancer cases and 50,260 cancer deaths in 2017. For patients with American Joint Committee on Cancer (AJCC) stage I, II, and III colon cancer (locoregional, no distance metastasis), the main treatment is surgical resection. Adjuvant chemotherapy has become a recommended treatment for patients with stage III colon cancer (lymph node positive). Using adjuvant chemotherapy with fluorouracil for about 6 months, these patients have a $10 \%$ additional benefit in 5-year survival. ${ }^{3,4}$ However, for patients with stage II colon cancer (disease extends beyond the muscularis propria and lymph node negative), the advantage of adju- 
vant chemotherapy remains controversial. Most of previous studies including randomized controlled trials, meta-analyses, pooled analyses, and population-based analyses of patients with stage II colon cancer have no proof that adjuvant chemotherapy has overall improvement survival. ${ }^{5-9}$ Schrag et al investigated Medicare beneficiaries with stage II colon cancer who underwent adjuvant chemotherapy. After adjusting for differences among the groups known, the benefit of chemotherapy was uncertain (adjusted hazard ratio [aHR] for survival: 0.91, 95\% CI: 0.77-1.09). ${ }^{5}$ Another commonly cited prospective trial also did not make a big difference in survival benefit associated with adjuvant chemotherapy for stage II colon cancer subgroup (relative risk: 0.86 , 95\% CI: $0.66-1.12) .{ }^{7}$ On the contrast, another study carried out a pooled analysis of National Surgical Adjuvant Breast and Bowel Project adjuvant trials C-01 through C-05 with stage II and III colon cancer treated with surgery or with surgery plus 5-fluorouracil/leucovorin (5-FU/ LV). Adjuvant chemotherapy had been shown to improve overall survival (OS) in stage II (HR: 0.58, 95\% CI: 0.48-0.71) and III disease (HR: $0.65,95 \% \mathrm{CI}: 0.55-0.75) .{ }^{10}$

The American Society of Clinical Oncology (ASCO) suggests that there is no straightforward evidence from randomized controlled trials that recommend the routine use of adjuvant chemotherapy in patients with stage II colon cancer. ${ }^{11}$ The guidelines recommend the use of adjuvant chemotherapy for stage II colon cancer patients with poor prognostic factors. The poor prognostic factors include grade $3-4$, localized perforation or close, uncertain or positive margins, the invasion of lymphatic/vascular, bowel obstruction, neural invasion, elevated carcinoembryonic antigen level, need for emergent operation, T4 stage (expansion to neighboring organs), and $\leq 12$ lymph nodes examined. ${ }^{3,11-14}$

The number of lymph nodes examined is an important prognostic factor for stage II colon cancer in almost all guiding principles. Most previous studies showed that a benchmark of examining 1213 lymph nodes was not reached in the resected samples, which is related to bad prognosis in patients with stage II colon cancer. ${ }^{15-18}$ Swanson et al investigated the connection of the number of lymph nodes examined to the prognosis of T3N0M0 stage colon cancer. The 5-year relative survival rate of this stage varied from $64 \%$ ( 1 or 2 lymph nodes examined) to $86 \%$ (>25 lymph nodes examined). ${ }^{15}$ Chen and Bilchik queried the Surveillance, Epidemiology and End Results (SEER)-Medicare database for all stage I, II, and III colon cancer patients undergoing resection between 1988 and 2000. Multivariate regression analysis showed that patients with at least 15 nodes had a $20.6 \%$ reduction in mortality compared with 1-7 nodes, which had nothing to do with other patients and tumor characteristics. ${ }^{16}$ In contrast, a recent study by Moore et al demonstrated that the average number of nodes identified per specimen by the surgeon or hospital for stage I-III colon cancer did not significantly alter the relationship between number of nodes and survival adjusting for selected demographic characteristics. ${ }^{19}$ Although the number of lymph nodes examined could be an indication of adjuvant therapy, its use in this setting is still controversial. The objective of this study was to determine the benefit of adjuvant chemotherapy in patients with stage II colon cancer based on the number of lymph nodes examined, which was not observed in previous studies.

\section{Patients and methods Sources of data}

In our study, the linked SEER-Medicare database was used. The SEER project, developed by the National Cancer Institute (NCI), currently gathers and releases data on cancer incidence and survival in 17 registries, covering about $26 \%$ of the population of the USA. ${ }^{20}$ Medicare covers $97 \%$ of the population in the USA, mainly people aged 65 years and older. ${ }^{21}$ The linked SEER-Medicare database provides detailed information on elderly cancer patients, and is a unique and enormous source of information for health outcomes research and longitudinal epidemiologic surveys. ${ }^{19,21}$ The data accessed from SEER are freely available.

\section{Research object definition}

All patients diagnosed with primary colon cancer (SEER codes for cancer site: 18.0-18.9, codes for behavior: 3 ) in a SEER area from 1999 to 2004 were checked for eligibility to be included in our study. Patients with more than one primary tumor in lifetime were excluded. We included patients aged 66 years and older because we needed 1 year's information before diagnosis to look for comorbidity, and patients aged less than 65 years in Medicare data are patients with disability or end-stage renal disease. We included patients who enrolled in both part $\mathrm{A}$ and $\mathrm{B}$, but excluded patients enrolled in $\mathrm{HMO}$ plans as these insurers were not required to submit detailed claims to the Health Care Financing Administration. ${ }^{5}$

Patients whose cancer was reported on death certificates or at autopsies were excluded. Adenocarcinomas were stipulated to adopt SEER encipher for histology (814x, 8210-11, 8220$21,8260-63,8440,8480-81,8490) .{ }^{22,23}$ Patients with stage II disease were identified based on the information available on distant spread, tumor size, and nodal involvement in the SEER database $^{5}$ and classified on the basis of the AJCC staging system. We searched Medicare claims records for patients who underwent colon cancer-directed surgery within 3 months after primary diagnosis. Operations were defined on the basis of the International Classification of Disease, Ninth Revision, Clinical Modification (ICD-9-CM) procedure codes (45.7x, 45.8x, 48.4x, 
48.5x, and 48.6x) and Health Care Common Procedure Coding System/Current Procedural Terminology (HCPCS/CPT) codes (4414x, 4415x, 4416x, 44204-44208, and 4421x). ${ }^{5,24}$ The number of examined lymph nodes for patients with cancer directed surgery were also measured. ${ }^{5,15}$ Patients who survived less than 3 months after surgery were excluded because adjuvant therapy had nothing to do with immediate death after surgery. ${ }^{5}$

Patients were considered chemotherapy recipients if they had at least one claim document for chemotherapeutic administration, treatment, or agents in any Medicare claim files within 3 months after primary diagnosis. Chemotherapy claims included ICD-9-CM diagnosis codes (V58.1, V66.2, and V67.2), ICD-9-CM procedure code (99.25), HCPCS/CPT codes (Q0083-Q0085, 964xx, 965xx, J8510, J852x, J8530, J856x, J8600, J8610, J870x, J8999, and J9xxx), and revenue center codes $\left(0331,0332\right.$, and 0335)..$^{5,25,26}$

\section{Patient characteristics}

Patients' characteristics included demographic factors (age at diagnosis, marital status, race/ethnicity, gender, and SEER registration), socioeconomic factors (education and income), comorbidity, tumor factors (year of diagnosis and grade), and treatment factors (surgery, admission type, type of surgery, chemotherapy, and the number of lymph nodes examined). All demographics and tumor factors were obtained from the records in Patient Entitlement and Diagnosis Summary File (PEDSF) (the rights of patients and the diagnosis of the file). Unlike the USA Census, SEER-Medicare does not separate race and ethnicity. In our analysis, race/ethnicity was classified as non-Hispanic white, black, Hispanic, and other (Asian, Native American, and unknown people), like previous study. ${ }^{27}$

Education and income were estimated at the census tract level using 2000 Census data in PEDSF. Education level was estimated as percent of adults age $\geq 25$ who had younger than 12 years of education. The income level is estimated to be the median annual income, adjusted according to the family size. Both of these socioeconomic factors were categorized into quartile groups. ${ }^{28}$

A modified Charlson comorbidity index, which excluded diabetes and cancer from index, was used to calculate patient comorbidity. We used all Medicare claims files (MEDPAR: inpatient claims, OUTPAT: outpatient claims, and $\mathrm{NCH}$ : bills from physicians and other providers) from 12 months before primary cancer diagnosis until 3 months after diagnosis to calculate the modified Charlson comorbidity index and assign patients the maximal comorbidity observed. ${ }^{5}$

\section{Interest variable}

OS and disease-free survival (DFS) were our primary and secondary outcome result variables, respectively. OS was calculated from the date of colon cancer-directed surgery until the date of death or until the time of censoring, 31st December 2006. DFS was measured from the date of cancer diagnosis until the date of recurrence claim or until the time of censoring. Those patients who had one of the following three criteria were considered as having disease recurrence: ICD-9-CM diagnosis coding transfer (196.x, 197.x, and 198.x), additional chemotherapy after 12 months from death from cancer, or primary diagnosis. ${ }^{29}$ Our main concern was adjuvant chemotherapy.

\section{Statistical analysis}

According to each demographic or clinical characteristic, the rates of adjuvant chemotherapy use were assessed for grouped patients. Multivariate logistic regression controlling other confounding variables of latent confounding was adopted to evaluate whether specific factors were independently related to adjuvant chemotherapy. Kaplan-Meier survival curves for OS and DFS stratified by adjuvant chemotherapy status were generated. Multivariate Cox proportional hazard models were used to estimate fully adjusted hazard ratios (HRs) and 95\% CIs for adjuvant chemotherapy on overall survival and disease-free survival. The fully adjusted models were controlled for all factors of clinical interest, including age at diagnosis, education, income, year of diagnosis, gender, marital status, comorbidity, SEER registry, admission type, type of surgery, race/ethnicity, grade, and the number of lymph nodes examined. To find out who really needs adjuvant chemotherapy among patients with stage II colon cancer, the survival tests were also stratified by some potential prognostic factors, such as race/ethnicity, age, admission type, gender, type of surgery, grade, and number of lymph nodes examined. Potential interactions of interested variables were tested. We used multivariate logistic regression to construct propensity scores, which represent the index of the probability of treatment acceptance in each patient, and then compared the five quantiles of each propensity score quintile., 50 $P<0.05$ (two sided) was used as the cutoff point for statistical significance for individual variables. SAS software (version 9.2; SAS Institute Inc., Cary, NC, USA) was used to conduct all statistical analyses. $P<0.05$ (two sided) was used as the dividing point of the statistical significance of individual variables.

\section{Results}

Percentage of adjuvant chemotherapy use In total 9,651 patients were incorporated in our final cohort; $2,015(20.88 \%)$ received adjuvant chemotherapy. The claim between designated fluorouracil and leucovorin recipients was $86.99 \%$. The patient demographics are listed in Table 1, including socioeconomic status, comorbidity score, tumor 
Table I Baseline characteristics of the cohort and the percentage treated with adjuvant chemotherapy

\begin{tabular}{|c|c|c|c|c|}
\hline \multirow[t]{2}{*}{ Characteristics } & \multirow[t]{2}{*}{$\mathbf{N}(\%)$} & \multirow[t]{2}{*}{ \% Chemotherapy } & \multicolumn{2}{|c|}{ Adjusted odds ratio ${ }^{a}$} \\
\hline & & & OR (95\% CI) & $P$-value \\
\hline Total cohort & $9,651(100)$ & 20.88 & & \\
\hline \multicolumn{5}{|l|}{ Age (years) } \\
\hline $66-70$ & $1474(15.27)$ & 41.93 & I.0 (referent) & \\
\hline $7 I-75$ & $2003(20.75)$ & 33.20 & $0.689(0.595-0.798)$ & $<0.0001$ \\
\hline $76-80$ & $2349(24.34)$ & 20.86 & $0.373(0.320-0.435)$ & $<0.0001$ \\
\hline 81 and older & $3825(39.63)$ & 6.33 & $0.099(0.083-0.118)$ & $<0.0001$ \\
\hline \multicolumn{5}{|l|}{ Gender } \\
\hline Male & $3667(38.00)$ & 23.78 & I.0 (referent) & \\
\hline Female & $5984(62.00)$ & 19.10 & $0.944(0.840-1.061)$ & 0.3356 \\
\hline \multicolumn{5}{|l|}{ Race } \\
\hline White & 8221 (85.48) & 20.58 & I.0 (referent) & \\
\hline Black & $615(6.39)$ & 18.54 & $0.725(0.566-0.928)$ & 0.0107 \\
\hline Hispanic & $363(3.77)$ & 26.72 & $1.122(0.85 I-1.480)$ & 0.4132 \\
\hline Other & $419(4.36)$ & 24.34 & $1.088(0.818-1.446)$ & 0.5628 \\
\hline \multicolumn{5}{|l|}{ Marital status } \\
\hline Married & $4516(48.80)$ & 26.57 & I.0 (referent) & \\
\hline Not married & $4739(51.20)$ & 15.55 & $0.738(0.654-0.832)$ & $<0.0001$ \\
\hline \multicolumn{5}{|l|}{ Education } \\
\hline Lowest education & $2410(24.97)$ & 21.54 & I.0 (referent) & \\
\hline 2nd quartile & $2415(25.02)$ & 21.12 & $1.012(0.848-1.208)$ & 0.8926 \\
\hline $3 r d$ quartile & $24 I I(24.98)$ & 20.36 & $1.003(0.82|-| .225)$ & 0.9770 \\
\hline Highest education & $2415(25.02)$ & 20.50 & $0.986(0.783-\mid .24 I)$ & 0.9047 \\
\hline \multicolumn{5}{|l|}{ Income } \\
\hline Lowest income & $24 \mid 3(25.00)$ & 20.76 & 1.0 (referent) & \\
\hline 2nd quartile & $2415(25.02)$ & 20.83 & $1.009(0.847-1.203)$ & 0.9161 \\
\hline $3 r d$ quartile & $2412(24.99)$ & 20.48 & $0.982(0.802-1.204)$ & 0.8639 \\
\hline Highest income & $24 I I(24.98)$ & 21.44 & $1.003(0.788-1.275)$ & 0.9828 \\
\hline \multicolumn{5}{|l|}{ Comorbidity ${ }^{\mathrm{b}}$} \\
\hline 0 & $6816(70.62)$ & 22.10 & I.0 (referent) & \\
\hline 1 & $2057(21.31)$ & 19.11 & $0.846(0.736-0.97 I)$ & 0.0178 \\
\hline 2 and more & $778(8.06)$ & $14.9 \mid$ & $0.606(0.484-0.760)$ & $<0.0001$ \\
\hline \multicolumn{5}{|l|}{ Year of diagnosis } \\
\hline 1999 & $900(9.33)$ & 22.33 & I.0 (referent) & \\
\hline 2000 & $1740(18.03)$ & 24.08 & $1.027(0.824-1.279)$ & 0.8149 \\
\hline 2001 & $1773(18.37)$ & 21.21 & $0.860(0.691-1.070)$ & 0.1767 \\
\hline 2002 & $176 \mid(18.25)$ & 21.58 & $0.884(0.710-1.100)$ & 0.2692 \\
\hline 2003 & $1773(18.37)$ & 19.80 & $0.770(0.617-0.960)$ & 0.0204 \\
\hline 2004 & $1704(17.66)$ & 16.90 & $0.627(0.499-0.787)$ & $<0.0001$ \\
\hline \multicolumn{5}{|l|}{ SEER registry } \\
\hline California & $2776(28.76)$ & 21.04 & I.0 (referent) & \\
\hline Connecticut & 770 (7.98) & 14.29 & $0.70 \mathrm{I}(0.547-0.898)$ & 0.0049 \\
\hline Detroit & $74 \mid(7.68)$ & 24.02 & $1.298(1.037-1.625)$ & 0.0229 \\
\hline Hawaii & $132(1.37)$ & 21.97 & $0.882(0.542-1.438)$ & 0.6156 \\
\hline lowa & $1011(10.48)$ & 19.98 & $0.882(0.710-1.096)$ & 0.2580 \\
\hline New Mexico & $210(2.18)$ & 23.33 & $0.786(0.530-1.165)$ & 0.2310 \\
\hline Seattle & $504(5.22)$ & 15.48 & $0.617(0.464-0.822)$ & 0.0009 \\
\hline Utah & $206(2.13)$ & 21.36 & $0.903(0.619-1.318)$ & 0.5979 \\
\hline Atlanta & $266(2.76)$ & 18.42 & $0.807(0.568-1.148)$ & 0.2338 \\
\hline Rural Georgia & $36(0.37)$ & 22.22 & $0.837(0.352-1.993)$ & 0.6879 \\
\hline Kentucky & $764(7.92)$ & 24.08 & $1.116(0.878-1.419)$ & 0.3698 \\
\hline Louisiana & $665(6.89)$ & 22.41 & $0.936(0.736-1.191)$ & 0.5906 \\
\hline New Jersey & $1570(16.27)$ & 22.36 & $1.187(0.996-1.415)$ & 0.0556 \\
\hline \multicolumn{5}{|l|}{ Admission type } \\
\hline Elective & $4677(48.46)$ & 21.62 & I.0 (referent) & \\
\hline Urgent & $1372(14.22)$ & 20.48 & $1.068(0.902-1.266)$ & 0.4442 \\
\hline Emergent & $1175(12.17)$ & 18.98 & $1.108(0.920-1.333)$ & 0.2793 \\
\hline Unknown & $2427(25.15)$ & 20.60 & $1.109(0.967-1.272)$ & 0.1403 \\
\hline
\end{tabular}




\begin{tabular}{|c|c|c|c|c|}
\hline \multirow[t]{2}{*}{ Characteristics } & \multirow[t]{2}{*}{$\mathbf{N}(\%)$} & \multirow[t]{2}{*}{ \% Chemotherapy } & \multicolumn{2}{|c|}{ Adjusted odds ratio ${ }^{a}$} \\
\hline & & & OR $(95 \% \mathrm{Cl})$ & $P$-value \\
\hline \multicolumn{5}{|l|}{ Type of surgery } \\
\hline Without stoma & $8498(88.05)$ & 20.30 & I.0 (referent) & \\
\hline With stoma & $1153(11.95)$ & 25.15 & $1.300(1.103-1.532)$ & 0.0017 \\
\hline \multicolumn{5}{|l|}{ Grade } \\
\hline I & $735(7.78)$ & 20.14 & I.0 (referent) & \\
\hline II & $6887(72.93)$ & 20.37 & $1.118(0.906-1.381)$ & 0.2979 \\
\hline III or IV & $1821(19.28)$ & 22.84 & $1.452(1.147-1.838)$ & 0.0019 \\
\hline \multicolumn{5}{|l|}{ Lymph nodes examined } \\
\hline$>12$ nodes examined & $4010(41.57)$ & 21.30 & I.0 (referent) & \\
\hline $1-12$ nodes examined & $5287(54.81)$ & $20.4 I$ & $0.984(0.879-1.103)$ & 0.7865 \\
\hline No node examined & $349(3.62)$ & 23.21 & $0.826(0.606-1.126)$ & 0.2264 \\
\hline
\end{tabular}

Notes: aControlled for age, gender, race/ethnicity, marital status, education, income, comorbidity, year of diagnosis, SEER registry, admission type, type of surgery, grade, and number of lymph nodes examined. 'Use modified Charlson comorbidity index without cancer.

factors and treatment factors, and the percentage in each subgroup who received adjuvant chemotherapy. Most (54.8\%) patients had only 1-12 lymph nodes examined, and only $41.6 \%$ had $>12$ nodes examined. The following characteristics were higher for each independent association with adjuvant chemotherapy rates: younger, white race or Hispanic, married, lower comorbidity, surgery with stoma, poor, or undifferentiated, whereas gender, education status, income status, the urgency of the hospital admission, and the number of lymph nodes examined in the surgery specimen were not. There was a trend toward decreasing the use of adjuvant chemotherapy for patients diagnosed in recent years $(P<0.0001)$. The percentage of adjuvant chemotherapy varied from minimum of $14 \%$ in Connecticut to maximum of $24 \%$ in Detroit and Kentucky. No significant interaction was found between chemotherapy and other factors of interest.

\section{Association between adjuvant chemotherapy and survival}

The Kaplan-Meier survival curves are shown in Figure 1. The 5-year survival rate of patients without adjuvant chemotherapy was $60 \%$, and the 5 -year survival rate of patients with adjuvant chemotherapy was $76 \%$. The unadjusted HR was 0.553 (95\% CI: $0.502-0.610, P<0.0001)$. Controlling for all potential confounders, the result remained significant (aHR: $0.766,95 \%$ CI: $0.688-0.853, P<0.0001$ ). Propensity score analysis yielded similar results. In fully adjusted model, adjuvant chemotherapy was also related to increased DFS in our cohort (aHR: 0.80 ; 95\% CI: 0.70-0.92).

Table 2 lists the risk ratios and 95\% CI associated with patient characteristics and OS. No adjuvant chemotherapy, older age, male sex, not-married status, higher comorbidity, the urgency of hospital admission, surgery with stoma, higher grade, and the number of lymph nodes examined were each independently related with worse survival. Neither race/ ethnicity, nor education status, nor income status was an independent predictor of survival.

\section{Subgroup analyses of association between treatment and survival}

To find out what kind of patients with stage II colon cancer can really benefit from adjuvant chemotherapy, we conducted subgroup analyses for different potential treatment indicators. Figures $2-5$ show the results of survival analyses associated with adjuvant chemotherapy in different subgroups. Figure 2 shows the survival analyses in different subgroups on the basis of the number of lymph nodes examined. Figure 6 shows the Kaplan-Meier curve by number of nodes examined. Although adjuvant chemotherapy was related to our cohort improvement, its beneficial effects on OS (HR: $0.73 ; 95 \%$ CI: $0.64-0.83$ ) and DFS (HR: $0.71 ; 95 \%$ CI: $0.60-0.85$ ) were limited to patients with 0-12 lymph nodes. Similar results can be seen in patients with grade II-IV colon cancer and emergency surgery.

\section{Discussion}

The benefit of adjuvant chemotherapy remains controversial in patients with stage II colon cancer. Despite data suggesting that some poor prognostic features, such as failure to meet a benchmark of 12-13 lymph nodes in resection specimens, are associated with worse prognosis in patients with stage II colon cancer and may be an indication for adjuvant therapy, their use in this setting also remains controversial. In this study, we used a population-based database, SEER-Medicare, to determine the benefit of chemotherapy in patients with stage II colon cancer cohort, and also in some subgroups according to some poor prognostic characteristics, especially 


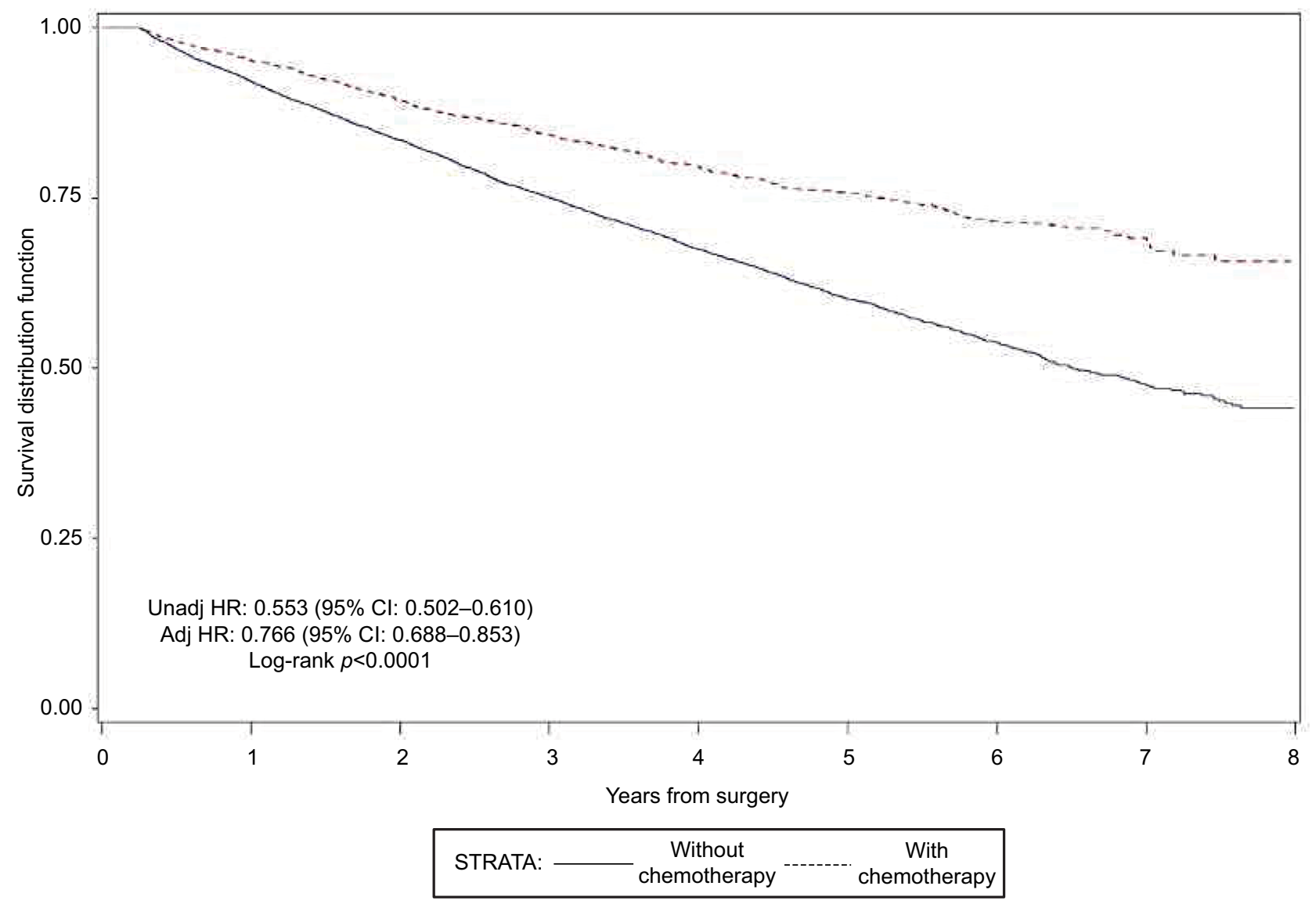

Figure I The effects of adjuvant chemotherapy on overall survival. Abbreviations: Unadj, unadjusted; HR, hazard ratio; Adj, adjusted.

the number of lymph nodes examined. To our knowledge, it is the first study to show that although adjuvant chemotherapy was related to improved OS (HR: $0.766,95 \% \mathrm{CI}$ : $0.688-0.853, P<0.0001)$ and DFS (HR: $0.802,95 \% \mathrm{CI}$ : $0.0 .698-0.922, P<0.0001)$ in our cohort, its beneficial effect on OS (HR: 0.728 ; 95\% CI: $0.637-0.833, P<0.0001$ ) and DFS (HR: 0.712 ; 95\% CI: $0.596-0.852, P<0.0001$ ) only exist in patients with 0-12 lymph nodes examined.

From 1999 to 2004, a sample of patients aged 66 years and older who had been diagnosed with stage II colon cancer was enrolled. We found that $20.88 \%$ of the patients received adjuvant chemotherapy. The age of diagnosis is closely related to the decision of treatment. Participants in the age group of 66-69 years had the highest rate of receiving adjuvant chemotherapy, and the rate decreased for older patients. In essence, African Americans had a lower rate of receiving adjuvant chemotherapy than Whites and other race/ethnicity, as described in a previous study. ${ }^{31}$ The rate of receiving adjuvant chemotherapy was lower in single patients than in married patients. Some of the clinical and tumor characteristics, such as lower comorbidity index score, surgery with stoma, and grade III or IV, were also associated with higher rates of adjuvant chemotherapy. By contrast, other characteristics including gender, socioeconomic status, admission type of surgery, or number of lymph nodes examined showed no significant association with adjuvant chemotherapy decision. These results are similar with a previous population-based analysis for Medicare patients with stage II colon cancer by Schrag et al. ${ }^{5}$

Most previous studies ${ }^{5-9}$ showed that adjuvant chemotherapy may limitedly improve OS; however, the benefit did not reach significance level. By contrast, one recent study conducted a pooled analysis and found advanced OS with adjuvant chemotherapy in stage II (HR: $0.58,95 \%$ CI: $0.48-0.71$ ) and stage III disease (HR: $0.65,95 \% \mathrm{CI}$ : 0.55-0.75).${ }^{10}$ In our study, using SEER-Medicare database, we included a total of 9,651 patients in our final cohort, and found that adjuvant chemotherapy was independently related to advanced OS and DFS in our cohort, after controlling for most potential confounders. The adequate sample size of our study is another important advantage over previous studies. It allowed to have sufficient power to detect significant differences in OS and DFS for patients with stage II colon cancer. 
Table 2 Hazard ratio for mortality according to patient characteristics

\begin{tabular}{|c|c|c|c|c|}
\hline \multirow[t]{2}{*}{ Characteristics } & \multicolumn{2}{|l|}{ Unadjusted model } & \multicolumn{2}{|l|}{ Adjusted model $^{\mathrm{a}}$} \\
\hline & OR $(95 \% \mathrm{Cl})$ & $P$-value & OR $(95 \% \mathrm{Cl})$ & $P$-value \\
\hline \multicolumn{5}{|c|}{ Adjuvant chemotherapy } \\
\hline No & I.0 (referent) & & I.0 (referent) & \\
\hline Yes & $0.553(0.502-0.610)$ & $<0.0001$ & $0.766(0.688-0.853)$ & $<0.0001$ \\
\hline \multicolumn{5}{|l|}{ Age (years) } \\
\hline $66-70$ & I.0 (referent) & & I.0 (referent) & \\
\hline $7 I-75$ & $1.333(1.149-1.546)$ & 0.0001 & $1.208(1.034-1.413)$ & 0.0176 \\
\hline $76-80$ & $1.693(1.47 \mid-1.948)$ & $<0.0001$ & $1.562(1.346-1.813)$ & $<0.0001$ \\
\hline 81 and older & $3.223(2.837-3.661)$ & $<0.0001$ & $2.691(2.338-3.097)$ & $<0.0001$ \\
\hline \multicolumn{5}{|l|}{ Gender } \\
\hline Male & I.0 (referent) & & I.0 (referent) & \\
\hline Female & $0.970(0.904-1.041)$ & 0.4035 & $0.797(0.735-0.864)$ & $<0.0001$ \\
\hline \multicolumn{5}{|l|}{ Race } \\
\hline White & I.0 (referent) & & I.0 (referent) & \\
\hline Black & $1.089(0.949-1.250)$ & 0.2244 & $0.984(0.84|-| .152)$ & $0.844 I$ \\
\hline Hispanic & $0.946(0.786-1.139)$ & 0.5572 & $1.095(0.896-1.340)$ & 0.3751 \\
\hline Other & $0.788(0.656-0.947)$ & 0.0110 & $0.763(0.619-0.939)$ & 0.0108 \\
\hline \multicolumn{5}{|l|}{ Marital status } \\
\hline Married & I.0 (referent) & & I.0 (referent) & \\
\hline Not married & $1.568(1.460-1.685)$ & $<0.0001$ & $1.299(1.198-1.409)$ & $<0.0001$ \\
\hline \multicolumn{5}{|l|}{ Education } \\
\hline Lowest education & I.0 (referent) & & I.0 (referent) & \\
\hline 2nd quartile & $0.911(0.828-1.002)$ & 0.0545 & $0.938(0.837-1.051)$ & 0.2711 \\
\hline $3 r d$ quartile & $0.895(0.813-0.986)$ & 0.0239 & $0.940(0.827-1.068)$ & 0.3418 \\
\hline Highest education & $0.866(0.786-0.954)$ & 0.0035 & $0.942(0.813-1.092)$ & 0.4276 \\
\hline \multicolumn{5}{|l|}{ Income } \\
\hline Lowest income & I.0 (referent) & & I.0 (referent) & \\
\hline 2nd quartile & $0.914(0.830-1.006)$ & 0.0665 & $0.979(0.874-1.096)$ & 0.7080 \\
\hline $3 r d$ quartile & $0.985(0.896-1.084)$ & 0.7618 & $1.100(0.966-1.254)$ & 0.1507 \\
\hline Highest income & $0.895(0.812-0.987)$ & 0.0260 & $1.045(0.895-1.221)$ & 0.5753 \\
\hline \multicolumn{5}{|l|}{ Comorbidity ${ }^{b}$} \\
\hline 0 & I.0 (referent) & & I.0 (referent) & \\
\hline 1 & $1.572(1.450-1.703)$ & $<0.0001$ & $1.438(1.322-1.564)$ & $<0.0001$ \\
\hline 2 and more & $2.209(1.985-2.457)$ & $<0.0001$ & $2.07 \mid(1.850-2.318)$ & $<0.0001$ \\
\hline \multicolumn{5}{|l|}{ Year of diagnosis } \\
\hline 1999 & I.0 (referent) & & I.0 (referent) & \\
\hline 2000 & $1.054(0.937-1.186)$ & 0.3808 & $0.976(0.859-1.108)$ & 0.7046 \\
\hline 2001 & $1.056(0.934-1.193)$ & 0.3856 & $0.953(0.836-1.085)$ & $0.464 I$ \\
\hline 2002 & $0.929(0.815-1.058)$ & 0.2667 & $0.850(0.74 I-0.976)$ & 0.0214 \\
\hline 2003 & $0.910(0.793-1.046)$ & 0.1840 & $0.866(0.748-1.003)$ & 0.0556 \\
\hline 2004 & $0.796(0.680-0.932)$ & 0.0047 & $0.753(0.638-0.890)$ & 0.0009 \\
\hline \multicolumn{5}{|l|}{ SEER registry } \\
\hline California & I.0 (referent) & & I.0 (referent) & \\
\hline Connecticut & $1.078(0.944-1.231)$ & 0.2650 & $1.050(0.911-1.210)$ & 0.5027 \\
\hline Detroit & $0.978(0.85 I-I .124)$ & 0.7564 & $0.954(0.820-1.110)$ & 0.5410 \\
\hline Hawaii & $0.746(0.532-1.046)$ & 0.0891 & $1.035(0.722-1.484)$ & 0.8509 \\
\hline lowa & $0.924(0.817-1.046)$ & 0.2144 & $0.945(0.821-1.086)$ & 0.4244 \\
\hline New Mexico & $0.786(0.603-1.025)$ & 0.0758 & $0.775(0.580-1.035)$ & 0.0846 \\
\hline Seattle & $0.979(0.833-1.152)$ & 0.8013 & $1.105(0.93|-| .3 \mid 3)$ & 0.2540 \\
\hline Utah & $0.878(0.686-1.123)$ & 0.2991 & $0.865(0.67 \mid-1.116)$ & 0.2648 \\
\hline Atlanta & $1.093(0.887-1.345)$ & 0.4042 & I.049 (0.84I-I.307) & 0.6734 \\
\hline Rural Georgia & $0.343(0.154-0.764)$ & 0.0088 & $0.273(0.113-0.659)$ & 0.0039 \\
\hline Kentucky & $1.152(1.007-1.318)$ & 0.0394 & $1.191(1.006-1.409)$ & 0.0424 \\
\hline Louisiana & $1.100(0.95 I-1.272)$ & 0.2001 & $1.140(0.971-1.338)$ & 0.1090 \\
\hline New Jersey & $1.049(0.943-1.167)$ & 0.3793 & $0.967(0.86 \mathrm{I}-1.086)$ & 0.5748 \\
\hline
\end{tabular}


Table 2 (Continued)

\begin{tabular}{|c|c|c|c|c|}
\hline \multirow[t]{2}{*}{ Characteristics } & \multicolumn{2}{|l|}{ Unadjusted model } & \multicolumn{2}{|l|}{ Adjusted model $^{\mathrm{a}}$} \\
\hline & OR $(95 \% \mathrm{Cl})$ & $P$-value & OR $(95 \% \mathrm{CI})$ & $P$-value \\
\hline \multicolumn{5}{|l|}{ Admission type } \\
\hline Elective & I.0 (referent) & & I.0 (referent) & \\
\hline Urgent & $1.560(1.407-1.730)$ & $<0.0001$ & $1.385(|.24|-\mid .546)$ & $<0.0001$ \\
\hline Emergent & $2.184(1.975-2.416)$ & $<0.0001$ & 1.748 (I.569-1.948) & $<0.0001$ \\
\hline Unknown & 1.771 (1.629-1.925) & $<0.0001$ & 1.511 (1.383-1.65I) & $<0.0001$ \\
\hline \multicolumn{5}{|l|}{ Type of surgery } \\
\hline Without stoma & I.0 (referent) & & I.0 (referent) & \\
\hline With stoma & 1.551 (I.4I2-I.703) & $<0.0001$ & $1.458(1.320-1.610)$ & $<0.0001$ \\
\hline \multicolumn{5}{|l|}{ Grade } \\
\hline I & I.0 (referent) & & I.0 (referent) & \\
\hline II & $1.173(1.020-1.349)$ & 0.0249 & $1.243(1.074-1.438)$ & 0.0035 \\
\hline III or IV & $1.353(1.161-1.577)$ & $<0.0001$ & $1.452(1.237-1.705)$ & $<0.0001$ \\
\hline \multicolumn{5}{|l|}{ Lymph nodes examined } \\
\hline$>12$ nodes examined & I.0 (referent) & & I.0 (referent) & \\
\hline $1-12$ nodes examined & $1.376(1.279-1.480)$ & $<0.0001$ & $1.306(1.210-1.410)$ & $<0.0001$ \\
\hline No node examined & $1.715(1.448-2.030)$ & $<0.0001$ & $1.667(1.384-2.008)$ & $<0.0001$ \\
\hline
\end{tabular}

Notes: aControlled for adjuvant chemotherapy, age, gender, race/ethnicity, marital status, education, income, comorbidity, year of diagnosis, SEER registry, admission type, type of surgery, grade, and number of lymph nodes examined. Use modified Charlson comorbidity index without cancer.

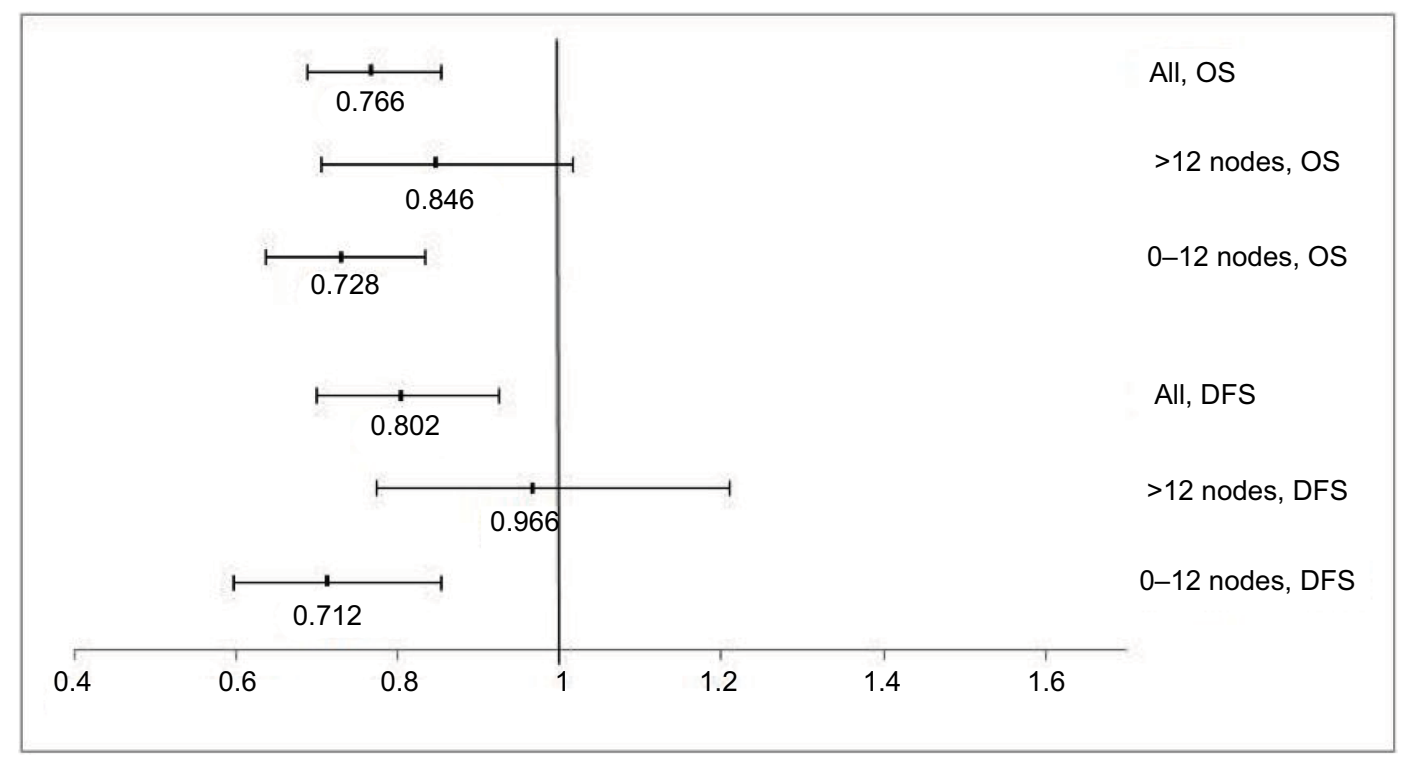

Figure 2 Hazard ratios and 95\% Cls associated with adjuvant chemotherapy for different subgroups according to number of lymph nodes examined. Abbreviations: OS, overall survival; DFS, disease-free survival.

In additional, we detected and quantized the independent HRs for potential prognostic factors in our fully adjusted multivariate analyses. In contrast to those with more than 12 lymph nodes examined, patients with 1-12 lymph nodes or with no lymph node examined had a $30.6 \%$ (HR: $1.306,95 \%$ CI: $1.210-1.410, P<0.0001$ ) and a $66.7 \%$ (HR: $1.667,95 \%$ CI: $1.384-2.008, P<0.0001)$ higher risk of death, respectively. These results are similar with previous investigations. Swan- son et al demonstrated that for patients with T3N0M0 colon cancer that were surgically treated, three strata of lymph nodes (1-7, 8-12, and $\geq 13$ ) distinguished significantly different observed 5-year survival rates. ${ }^{15}$ The reason for the differences in survival based on the number of lymph nodes examined is understaging. ${ }^{15,18,19} \mathrm{~A}$ low number of lymph nodes examined may lead to missing positive lymph nodes inadvertently and incorrect staging of a patient with colon cancer. ${ }^{19}$ 


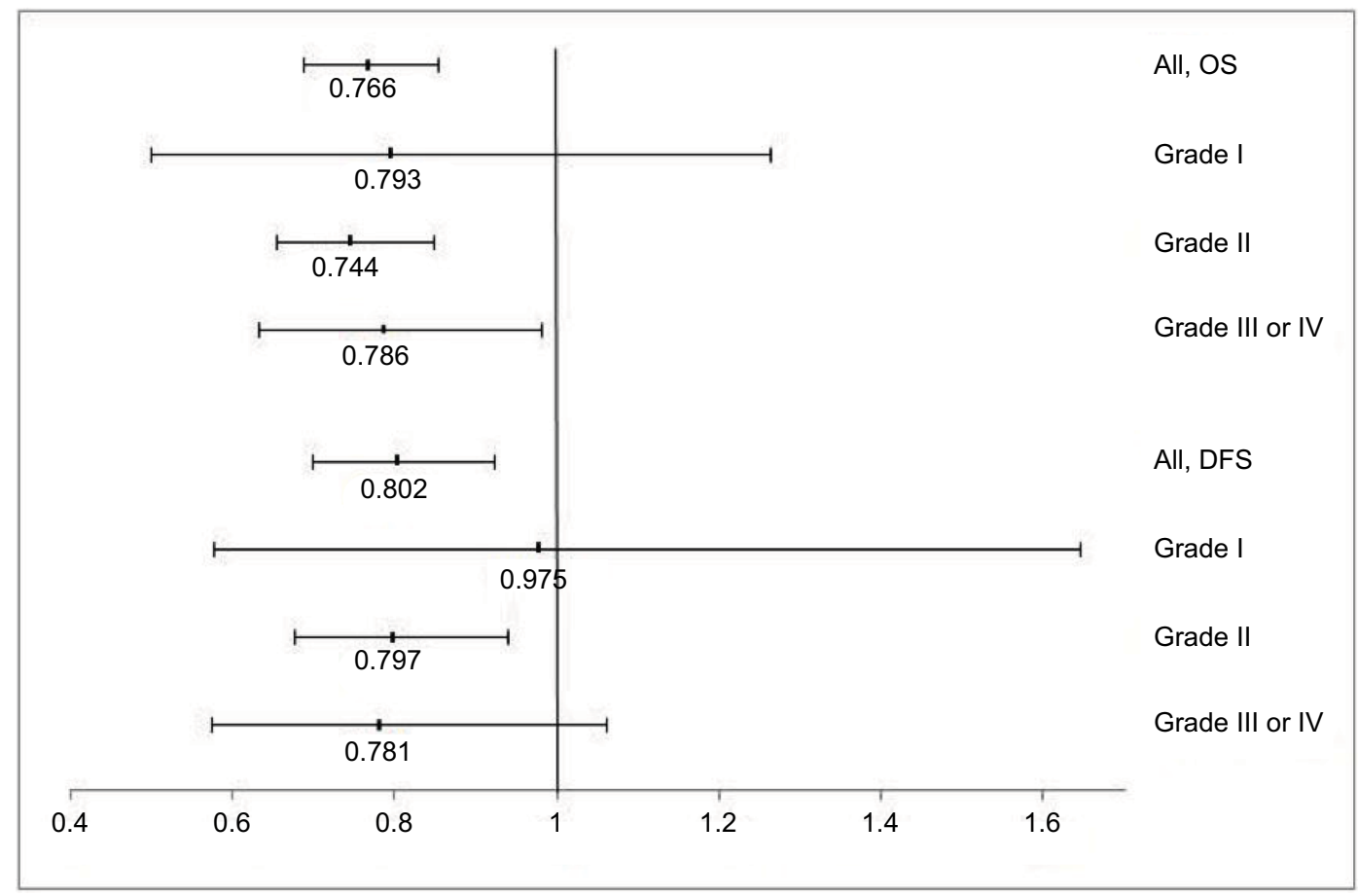

Figure 3 Hazard ratios and $95 \% \mathrm{Cls}$ associated with adjuvant chemotherapy for different subgroups according to grade. Abbreviations: OS, overall survival; DFS, disease-free survival.

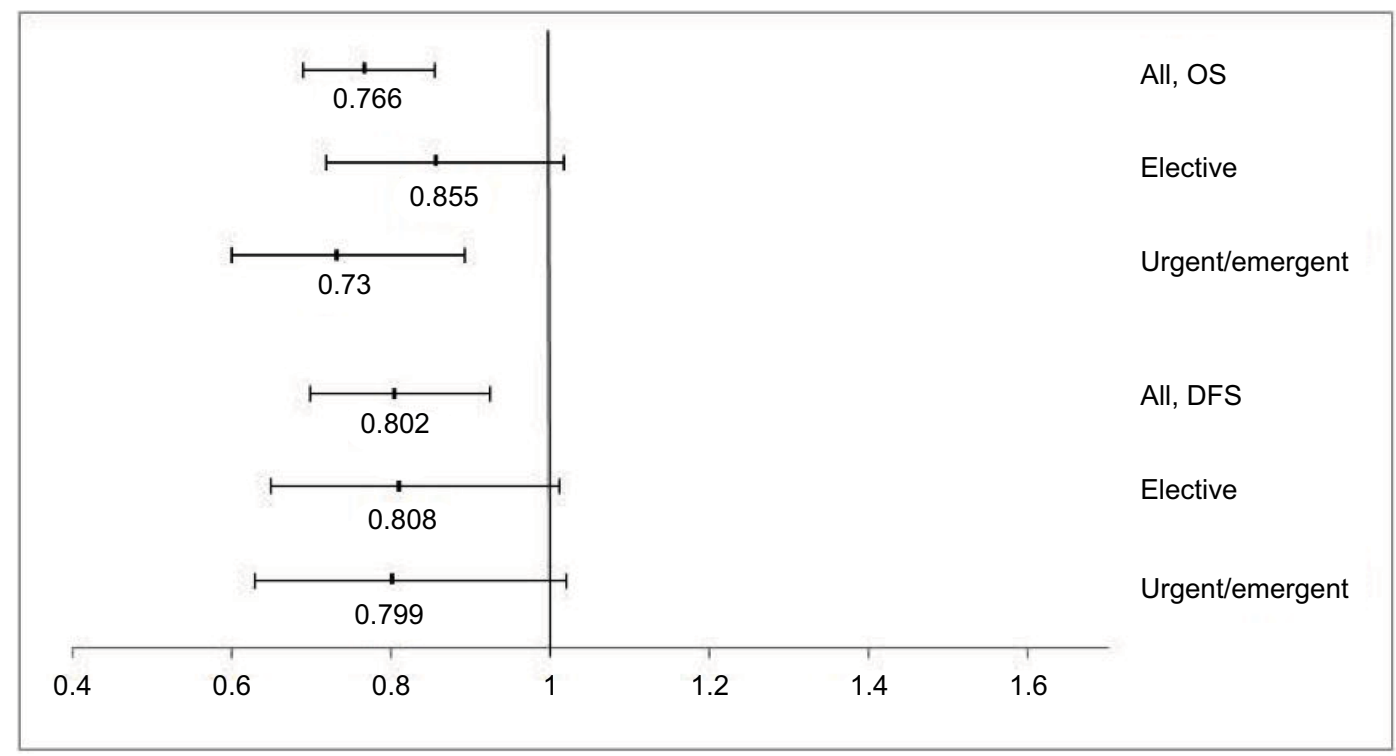

Figure 4 Hazard ratios and $95 \% \mathrm{Cls}$ associated with adjuvant chemotherapy for different subgroups according to admission type. Abbreviations: OS, overall survival; DFS, disease-free survival.

We also confirmed that other prognostic factors were independently related to survival. In contrast to those patients with elective surgery, patients with urgent surgery and emergent surgery had a $38.5 \%$ (HR: $1.385,95 \% \mathrm{CI}$ : $1.241-1.546, P<0.0001)$ and a $74.8 \%$ (HR: $1.748,95 \%$ CI: $1.569-1.948, P<0.0001)$ higher risk of death, respectively. Patients who had surgery with stoma had a $45.8 \%$
(HR: $1.458,95 \%$ CI: $1.320-1.610, P<0.0001)$ higher risk of death than patients without stoma. Compared to those patients with grade I colon cancer, patients with grade II tumor or with grade III-IV tumor had a $24.3 \%$ (HR: 1.243 , 95\% CI: $1.074-1.438, P=0.0035$ ) and a $45.2 \%$ (HR: 1.452 , 95\% CI: $1.237-1.705, P<0.0001)$ higher risk of death, respectively. All these results conformed to our clinical 


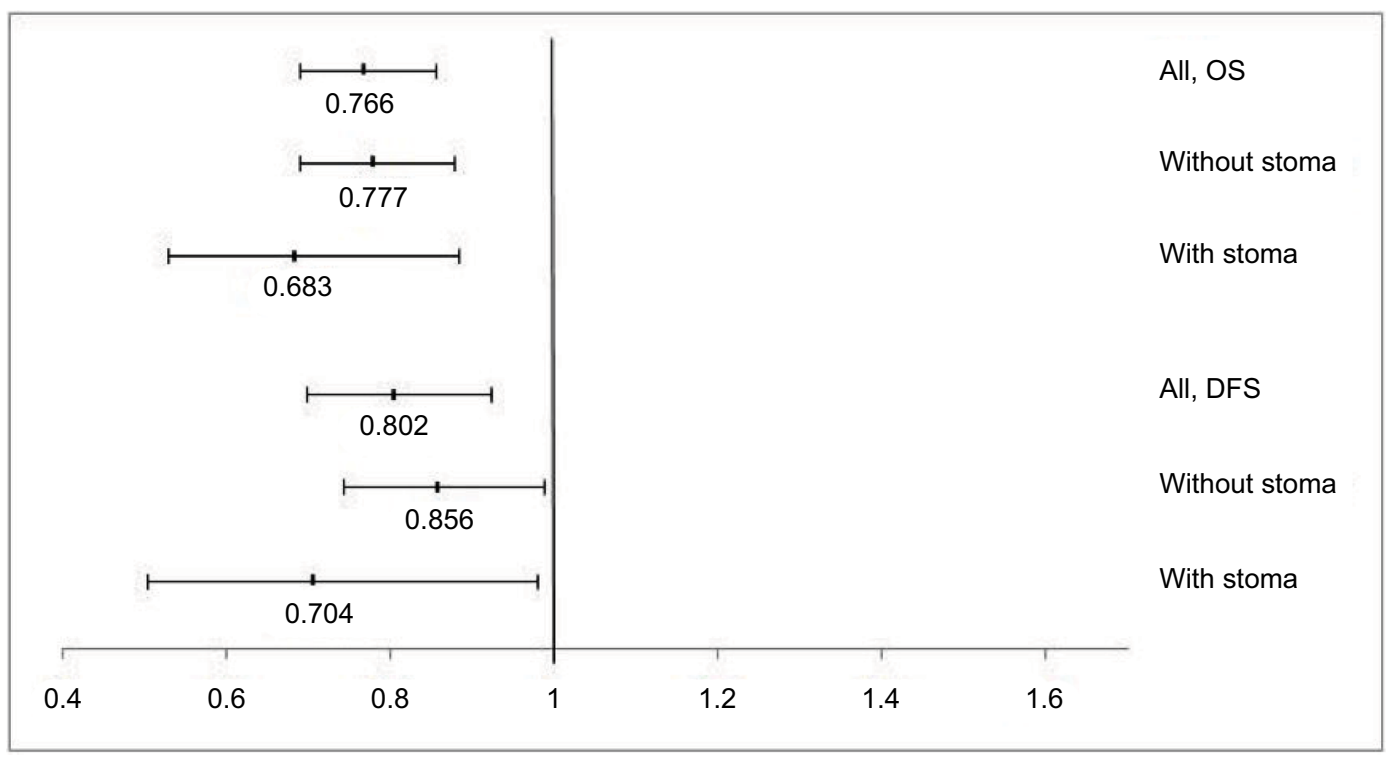

Figure 5 Hazard ratios and $95 \% \mathrm{Cls}$ associated with adjuvant chemotherapy for different subgroups according to type of surgery. Abbreviations: OS, overall survival; DFS, disease-free survival.

Adjuvant chemotherapy for stage II colon cancer

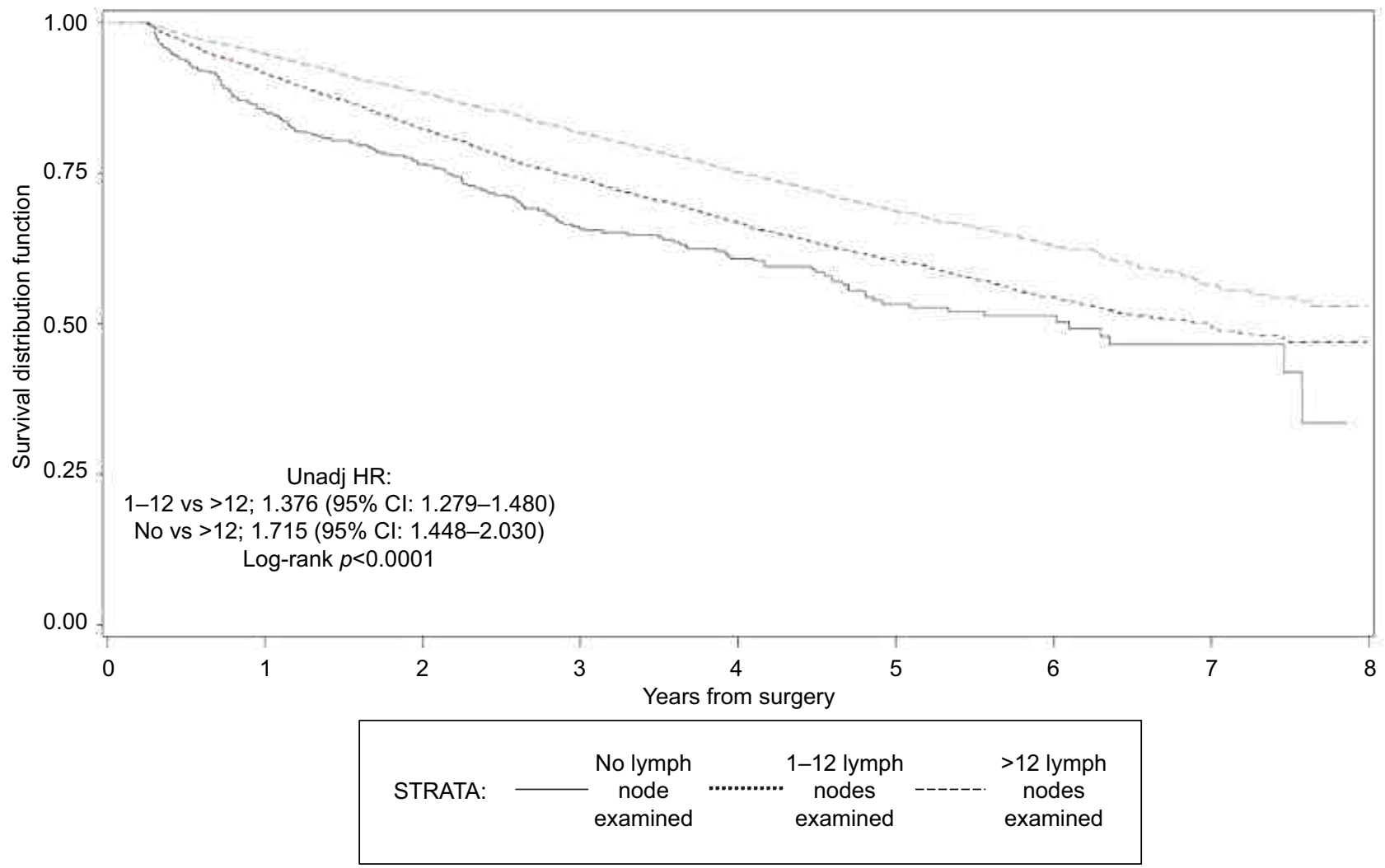

Figure 6 The effect of lymph nodes examined on overall survival.

Abbreviations: Unadj, unadjusted; HR, hazard ratio.

sense and general knowledge, and may be important foundation to support treatment decision.

Another important advantage of our study over previous studies is that we established multivariate models to estimate the advantage of adjuvant chemotherapy for subgroup of patients with specific prognostic factors in order to find out who may really need adjuvant chemotherapy. Previous investigations have shown that not all patients benefit from adjuvant chemotherapy except for some patients with stage II colon cancer. Factors that could reliably predict responses 
to adjuvant chemotherapy would be especially beneficial in patients with stage II colon cancer. In our research, we discovered that although adjuvant chemotherapy was related to improved outcomes, its beneficial effects on OS and DFS only exist in patients with $0-12$ nodes examined. The beneficial effect of adjuvant chemotherapy for patients with $>12$ lymph nodes examined did not reach significant level in fully adjusted model. Patients with $0-12$ nodes examined should be considered for adjuvant chemotherapy. Significant beneficial effects can also be seen in subgroup of patients with grade II-IV disease and in subgroup of patients with urgent/emergent surgery.

The advantage of adjuvant chemotherapy for patients with stage II colon cancer has been discussed for many years; however, the result still remains controversial. In our study, using population-based database, SEER-Medicare, we found that adjuvant chemotherapy was related to improved outcomes, and its beneficial effect on OS and DFS only exists in patients with $0-12$ nodes examined, or patients with grade I-III disease, or patients with urgent/emergent surgery. To our knowledge, this is the first research to confirm the benefit of adjuvant chemotherapy for subgroup of stage II colon cancer patients with specific prognostic factor. Now we can answer the important question: is it that patients with stage II colon cancer need adjuvant chemotherapy?

\section{Acknowledgment}

The abstract of this manuscript was presented at 2011 ASCO Annual Meeting.

\section{Disclosure}

The authors report no other conflicts of interest in this work.

\section{References}

1. Siegel RL, Miller KD, Jemal A. Cancer statistics, 2017. CA Cancer J Clin. 2017;67(1):7-30.

2. Esnaola NF, Gebregziabher M, Finney C, Ford ME. Underuse of surgical resection in black patients with nonmetastatic colorectal cancer: location, location, location. Ann Surg. 2009;250(4):549-557.

3. Gill S, Loprinzi CL, Sargent DJ, et al. Pooled analysis of fluorouracilbased adjuvant therapy for stage II and III colon cancer: who benefits and by how much? J Clin Oncol. 2004;22(10):1797-1806.

4. Sargent D, Sobrero A, Grothey A, et al. Evidence for cure by adjuvant therapy in colon cancer: observations based on individual patient data from 20,898 patients on 18 randomized trials. J Clin Oncol. 2009;27(6):872-877.

5. Schrag D, Rifas-Shiman S, Saltz L, Bach PB, Begg CB. Adjuvant chemotherapy use for Medicare beneficiaries with stage II colon cancer. $J$ Clin Oncol. 2002;20(19):3999-4005.

6. Schippinger W, Samonigg H, Schaberl-Moser R, et al; Austrian Breast and Colorectal Cancer Study Group. A prospective randomised phase III trial of adjuvant chemotherapy with 5-fluorouracil and leucovorin in patients with stage II colon cancer. Br J Cancer. 2007;97(8):1021-1027.
7. Quasar Collaborative Group, Gray R, Barnwell J, et al. Adjuvant chemotherapy versus observation in patients with colorectal cancer: a randomised study. Lancet. 2007;370(9604):2020-2029.

8. Mamounas E, Wieand S, Wolmark N, et al. Comparative efficacy of adjuvant chemotherapy in patients with Dukes' B versus Dukes' C colon cancer: results from four National Surgical Adjuvant Breast and Bowel Project adjuvant studies (C-01, C-02, C-03, and C-04). J Clin Oncol. 1999; 17(5):1349-1355.

9. Figueredo A, Charette ML, Maroun J, Brouwers MC, Zuraw L. Adjuvant therapy for stage II colon cancer: a systematic review from the Cancer Care Ontario Program in evidence-based care's gastrointestinal cancer disease site group. J Clin Oncol. 2004;22(16):3395-3407.

10. Wilkinson NW, Yothers G, Lopa S, Costantino JP, Petrelli NJ, Wolmark N. Long-term survival results of surgery alone versus surgery plus 5-fluorouracil and leucovorin for stage II and stage III colon cancer: pooled analysis of NSABP C-01 through C-05. A baseline from which to compare modern adjuvant trials. Ann Surg Oncol. 2010;17(4):959-966.

11. Benson AB 3rd, Schrag D, Somerfield MR, et al. American Society of Clinical Oncology recommendations on adjuvant chemotherapy for stage II colon cancer. J Clin Oncol. 2004;22(16):3408-3419.

12. Quah HM, Chou JF, Gonen M, et al. Identification of patients with high-risk stage II colon cancer for adjuvant therapy. Dis Colon Rectum. 2008;51(5):503-507.

13. Chang GJ, Rodriguez-Bigas MA, Skibber JM, Moyer VA. Lymph node evaluation and survival after curative resection of colon cancer: systematic review. J Natl Cancer Inst. 2007;99(6):433-441.

14. Chen HS, Sheen-Chen SM. Obstruction and perforation in colorectal adenocarcinoma: an analysis of prognosis and current trends. Surgery. 2000;127(4):370-376.

15. Swanson RS, Compton CC, Stewart AK, Bland KI. The prognosis of T3N0 colon cancer is dependent on the number of lymph nodes examined. Ann Surg Oncol. 2003;10(1):65-71.

16. Chen SL, Bilchik AJ. More extensive nodal dissection improves survival for stages I to III of colon cancer: a population-based study. Ann Surg. 2006;244(4):602-610.

17. Le Voyer TE, Sigurdson ER, Hanlon AL, et al. Colon cancer survival is associated with increasing number of lymph nodes analyzed: a secondary survey of intergroup trial INT-0089. J Clin Oncol. 2003;21(15):2912-2919.

18. Hashiguchi $\mathrm{Y}$, Hase $\mathrm{K}$, Ueno $\mathrm{H}$, et al. Prognostic significance of the number of lymph nodes examined in colon cancer surgery: clinical application beyond simple measurement. Ann Surg. 2010;251(5):872-881.

19. Moore J, Hyman N, Callas P, Littenberg B. Staging error does not explain the relationship between the number of lymph nodes in a colon cancer specimen and survival. Surgery. 2010;147(3):358-365.

20. About the SEER Program - SEER - Overview of the SEER Program; 2010. Available from:https://seer.cancer.gov/about/overview.html. Accessed July 10, 2018.

21. Warren JL, Klabunde CN, Schrag D, Bach PB, Riley GF. Overview of the SEER-Medicare data: content, research applications, and generalizability to the United States elderly population. Med Care. 2002;40(Suppl 8):IV-3-18.

22. SEER ICD-O-3 Coding Materials; 2009. Available from: https://seer. cancer.gov/icd-o-3/. Accessed July 10, 2018.

23. Schrag D, Panageas KS, Riedel E, et al. Surgeon volume compared to hospital volume as a predictor of outcome following primary colon cancer resection. J Surg Oncol. 2003;83(2):68-78; discussion 78-69.

24. Etzioni DA, Cannom RR, Madoff RD, Ault GT, Beart RW, Jr. Colorectal procedures: what proportion is performed by American board of colon and rectal surgery-certified surgeons? Dis Colon Rectum. 2010;53(5):713-720.

25. Obeidat NA, Pradel FG, Zuckerman IH, DeLisle S, Mullins CD. Outcomes of irinotecan-based chemotherapy regimens in elderly Medicare patients with metastatic colorectal cancer. Am J Geriatr Pharmacother. 2009;7(6):343-354. 
26. Warren JL, Harlan LC, Fahey A, et al. Utility of the SEER-Medicare data to identify chemotherapy use. Med Care. 2002;40(8 Suppl):IV-55-61.

27. Goodwin JS, Nguyen-Oghalai TU, Kuo YF, Ottenbacher KJ. Epidemiology of Medicare abuse: the example of power wheelchairs. JAm Geriatr Soc. 2007;55(2):221-226.

28. Du XL, Fang S, Coker AL, et al. Racial disparity and socioeconomic status in association with survival in older men with local/regional stage prostate carcinoma: findings from a large community-based cohort. Cancer. 2006;106(6):1276-1285.
29. Earle CC, Nattinger AB, Potosky AL, et al. Identifying cancer relapse using SEER-Medicare data. Med Care. 2002;40(8 Suppl): IV-75-81.

30. Lunceford JK. Stratification and weighting via the propensity score in estimation of causal treatment effects: a comparative study. Stat Med. 2017;36(14):2320.

31. Esnaola NF, Ford NE. Racial differences and disparities in cancer care and outcomes: where's the rub? Surg Oncol Clin NAm. 2012 Jul; 21(3): $417-437$.

\section{Publish your work in this journal}

Cancer Management and Research is an international, peer-reviewed open access journal focusing on cancer research and the optimal use of preventative and integrated treatment interventions to achieve improved outcomes, enhanced survival and quality of life for the cancer patient. The manuscript management system is completely online and includes a very quick and fair peer-review system, which is all easy to use. Visit http://www.dovepress.com/testimonials.php to read real quotes from published authors. 